\title{
New Jersey's approach to AIDS
}

\author{
MICHAEL BARNISH, DO \\ DAVID V. CONDOLUCI, DO
}

\begin{abstract}
The state of New Jersey, which now ranks fifth in the United States in total AIDS cases, has been especially motivated to develop a network of programs aimed toward curbing its own AIDS crisis. While the risk groups in the state are similar to those of the nation's overall, infection contracted via intravenous drug use comprises the majority of cases in New Jersey. The state has made great strides in addressing the problem of AIDS in this particular population, and its program is a model for other states to use or improve upon as the disease becomes more widespread.
\end{abstract}

Characterized by severe or total immune function suppression, by definition AIDS is associated with life-threatening opportunistic infections, such as Pneumocystis carinii pneumonia, or with malignancies, such as Kaposi's sarcoma. As of August 1987 , the CDC case definition ${ }^{1}$ includes encephalopathies as well.

Although homosexuals, intravenous drug abusers, Haitian immigrants, and recipients of blood products were the first infected groups in the United States, AIDS now has become widespread among sexual partners of infected persons and children of infected mothers. ${ }^{2}$ It is endemic to Haiti itself $^{3}$ and Central African nations ${ }^{4,5}$ as well. Today the emphasis is on high-risk behavior rather than high-risk groups.

By mid-December 1987 , more than 46,000 cases of AIDS had been documented in the United States. ${ }^{6}$ The US Public Health Services has estimated that there will be 323,000 reported AIDS patients by the end of 1991 , and that as many as 200,000 of them may be dead by that time. ${ }^{6}$

The mean interval between infection with hu- man immunodeficiency virus (HIV) and the onset of AIDS exceeds seven years. ${ }^{6}$ In one study, ${ }^{7} 36.5 \%$ of those infected with HIV developed the disease within 37 months. Among five other cohorts, the three-year post-HIV infection conversion to AIDS ranged from $8 \%$ to $34.2 \% .^{8} \mathrm{~A}$ recent study ${ }^{9}$ found that after being HIV infected for five years, 14 percent of all gay or bisexual men developed AIDS; the six- and seven-year incidences were $25 \%$ and $36 \%$, respectively. Ten-year conversions projections are as high as $50 \% .^{8}$

It is thought that AIDS patient soon will occupy $1 \%$ of all hospital beds in the United States and will account for $3 \%$ of all hospital costs. At present, direct health care costs in treating an AIDS patient lies anywhere between $\$ 77,000$ (Harvey Fineberg, MD, Harvard School of Public Health, press release, 1987) and $\$ 147,000 .{ }^{10}$ By the 1990 s, in the Bronx alone nearly half of the hospital beds will be devoted to patients with AIDS or AIDSrelated problems. ${ }^{11}$

Some positive findings do exist. There is evidence from the $\mathrm{CDC}^{6}$ that in some risk groups, the rate of new HIV infection may have declined somewhat from the incidences prevailing in the early $1980 \mathrm{~s}$. For example, identification of the implicating virus has reduced drastically the transmission of AIDS via blood transfusions. Also, a decline in the infection rate in homosexual men has occurred. This may reflect changes in sexual behaviors, such as the changes reported by a cohort of male homosexuals in San Francisco. ${ }^{12}$

The AIDS epidemic presents many medical, economic, and political challenges to public health officials. A primary obligation is to ensure that those with the disease receive appropriate and humane care. At the same time, the demands of the epidemic cannot be allowed to paralyze the hospital system, hence the need for alternate care arrangements. A knowledgeable and, therefore, rational 
general public is necessary to the development of these health care systems. While the CDC and the Public Health Service are among several groups that provide educational assistance on a national level, the state of New Jersey is making strides toward disease management within its own jurisdiction. New Jersey's program can be used as a role model for other states to use or to improve upon as AIDS becomes more widespread.

\section{New Jersey demographics}

New Jersey currently is rated fifth in the nation in total cases of AIDS. ${ }^{13}$ A total of 3,257 people in New Jersey have contracted AIDS; of these, 1,875 have died. ${ }^{13}$ The number of cases continue to climb sharply, although a recent adoption by the $\mathrm{CDC}^{1}$ of a more inclusive definition of AIDS makes precise comparisons between years difficult. Twenty-eight percent more cases have been reported in 1988 over 1987, but with under reporting problems, that figure is more likely to be nearer $50 \%$ to $60 \%{ }^{14}$ The number of cases in the state by 1991 is projected to exceed $10,000 .{ }^{14}$

Intravenous (IV) drug use is the most prevalent mode of transmission in the state. While the national rate for IV drug users approaches $16 \%$ among all AIDS patient, New Jersey's distribution is one in every two cases. Blacks comprise $50 \%$, whites $36 \%$, and Hispanics $14 \%$ of the total AIDS cases in New Jersey. ${ }^{16}$ Because IV drug use is concentrated within poor urban areas, a correlation to this distribution pattern is suggested. In a 1987 survey, ${ }^{15} 57 \%$ of female prostitutes tested in Newark-Jersey City-Patterson area were HIV-positive compared to $19 \%$ in Miami and 6\% in San Francisco. Half of the prostitutes interviewed nationally gave histories of IV drug abuse. The alarming number of IV drug users in New Jersey who have AIDS ultimately may be the bridge for AIDS developing in the general heterosexual community.

Homosexual or bisexual men who are not IV drug users comprise $38 \%$ of the New Jersey AIDS population, while those who use drugs intravenously as well comprise $7 \%$. AIDS infection from blood or blood component transfusions account for $2 \%$ of cases in New Jersey, while $1 \%$ of cases involve patients with hemophilia or other coagulation disorders of the total. Heterosexual persons who are not IV drug users comprise $8 \%$ of the total state AIDS cases, which is two times the national average. Three percent of all male AIDS patients are in this category, as are $27 \%$ of all female patients with AIDS. ${ }^{14}$

The most common age range at diagnosis in all cases is 30 to 39 years. Of all children with AIDS in New Jersey, 90\% have contracted the disease through parents with or at risk for AIDS. The suggested transmission in these instances is from an infected mother during the perinatal period. New Jersey ranks second only to New York State in the number of pediatric cases of AIDS. ${ }^{14}$

\section{New Jersey's service networks}

A network of services for local management of AIDS crisis presently is being coordinated by state legislators and public and private health groups throughout New Jersey. Because most of the state's cases involve IV drug users, the AIDS program is managed by the Division of Alcohol, Narcotic, and Drug Abuse Control of the New Jersey Department of Health. It is organized into six areas-surveillance, education and prevention, testing and counseling, treatment and community support, research, and laboratory services.

\section{Surveillance}

Since September 8, 1986, when new rule 8:57-1.14 ("Reporting of Acquired Immunodeficiency Syndrome and AIDS Related Complex") was adopted (New Jersey Register, October 6, 1986), more accurate reporting of the disease has been accomplished. The new rule provided for confidentiality, avoidance of duplication, and proper reporting procedures.

\section{Education and prevention}

The educational efforts of the New Jersey Department of Health began in 1984 with an AIDS hotline, which primarily provides target audiences with audiovisual materials. Since its inception, it has been screening thousands of calls each year.

A coupon program came into existence in 1986 in response to decreases in federal funding. Health educators have been distributing coupons redeemable for free initial outpatient drug detoxification services. The program has been so successful that, at the present time, new applications cannot be accepted.

Two mobile vans were outfitted early in 1987 . These units are aimed toward reaching people in poverty-stricken areas of Newark and Jersey City directly. Their primary purpose is the dissemination of information regarding AIDS and drug abuse. They also provide guides for well-baby care and provide referral services for those persons already infected with or concerned about contracting AIDS. Each mobile unit carries a physician and social worker among its staff, and physical examinations are available.

A first-of-its-kind prison program was initiated 
in June 1986; it offers AIDS information to previous IV drug abuse inmates who are due to be released on parole. Over 2,000 inmates participated during the program's first seven months.

Along similar lines, a system being coordinated by the Department of Health employs former drug addicts as counselors. Presently, 28 of these exaddicts are working statewide to disseminate information among drug users and street dealers in a peer-type fashion. This approach has met with fair success. For example, some "shooting gallery" operators now provide bleach and water solutions to disinfect needles and other drug paraphernalia. The importance of condom use also is being emphasized.

An educational program addressing the pediatric AIDS population is being developed at Children's Hospital of New Jersey.

\section{Testing and counseling}

There currently are nine regional AIDS counseling centers in the state; most are funded by New Jersey Department of Health grants. Most provide free, anonymous HIV-antibody testing, as well as AIDS information, for all state residents. Counseling services are the primary function of the centers, and, although most of the clients are male, many centers target their services toward highrisk female populations.

Many other existing support agencies have expanded their services to include AIDS patients. These agencies include the Hyacinth Foundation (based in New Brunswick) and the AIDS Project of the New Jersey Lesbian and Gay Coalition, which provides many services, including technical assistance to and coordination with other AIDS support groups. An AIDS Helpline telephone service also is in operation.

In southern New Jersey, AIDS Task Force affiliated with the Camden Area Health Education Centers provides education and counseling to residents in the Camden County area, while a New Jersey Alliance also provides support for Atlantic, Ocean, and Cape May counties.

\section{Treatment and community support}

The state is in the forefront in developing health care organizations and support systems for AIDS patients. Most patients are well enough to not require acute-level hospital care. Therefore, a continuum of services outside the hospital is of high priority. In January 1987, New Jersey became the first state to be granted a Medicaid waiver, whereby persons with AIDS could receive Medicaid funds for services performed outside of hospi- tals or skilled nursing or intensive care facilities. The program is expected to serve 1,650 people by its third year.

In addition to a \$3.2-million foundation grant to develop case managers in six northern New Jersey hospitals, medical day care centers and residential drug treatment beds for drug abusers with AIDS are being provided. Legal services to help those with AIDS draw up wills and deal with problems relating to employment, housing, and insurance discrimination are being initiated.

One program unique in the nation is the development of a dental care facility to serve AIDS patients. It is affiliated with the UMDNJ-SOM and is to be located in Newark.

\section{Home health care}

Home treatment for AIDS patients is provided statewide by various home health care services. Visiting nurse aides for patients on long-term IV drug therapy or for those who need more intensive care also are available. However, while insurance companies cover the costs of such treatment, many AIDS patients have little or no financial resources to cover these expenses, usually because of lack of family support or insufficient insurance coverage. Because the widespread fear of exposure has caused many aides to refuse to care for AIDS patients, a number of home health services find it difficult to meet staff requirements. ${ }^{16}$ It seems that home health care is one area that requires further attention and more effective coordination.

\section{Comment}

Beside support and therapy, a crucial step toward curbing HIV transmission is community education, with the end goal alteration of behaviors of highrisk groups. New Jersey is taking this approach against the AIDS epidemic. While voluntary support exists throughout the gay community, there is no such network for IV drug users, most of whom have no access to the resources they need. Anything less than a well-coordinated system of support groups, health clinics, and educational prevention programs will fail.

In the last two years, New Jersey has quadrupled its spending on AIDS research and prevention (to $\$ 8.2$ million yearly), and progress is being made. However, the formidable task has only begun, and as the number of AIDS cases multiplies, even more time and financial resources will become necessary.

1. Revision of the CDC surveillance case definition for acquired immu- 
nodeficiency syndrome. MMWR 1987;36(suppl):3S-15S.

2. Additional recommendations to reduce sexual and drug abuse-related transmission of human T-lymphotropic virus type III/lymphadenopathyassociated virus. MMWR 1986;35:152-155.

3. Pape JW, Liautaud B, Thomas F, et al: Characteristics of the acquired immunodeficiency syndrome (AIDS) in Haiti. N Engl J Med 1983;309:945. 950.

4. Van de Perre P, Rouvroy D, Lepage P, et al: Acquired immunodeficiency syndrome in Rwanda. Lancet 1984;2:62-65.

5. Piot P, Quinn TC, Taelman H, et al: Acquired immunodeficiency syndrome in a heterosexual population in Zaire. Lancet 1984;2:65-69.

6. Human immunodeficiency virus infection in the United States. MMWR 1987;36:801-804.

7. Holzman RS, Walsh CM, Karpatkin S: Risk for the acquired immunodeficiency syndrome among thrombocytopenic and nonthromboyctopenic homosexual men seropositive for the human immunodeficiency virus. Ann Intern Med 1987;106:383-386.

8. Goedert JJ, Biggar RJ, Weiss SH, et al: Three-year incidence of AIDS in five cohorts of HTLV-III-infected risk group members. Science $1986 ; 231: 992-995$

9. Centers for Disease Control. Demographics and projections 1986 1991. Coolfont Planning Conferences, June 1986.

10. Hardy AM, Rauch K, Echenberg D, et al: The economic impact of the first 10,000 cases of acquired immunodeficiency syndrome in the United States. JAMA 1986;255:209-211.
11. Friedland G: Epidemiology of AIDS. Presented at Lessons for Infection Control, Nosocomial Infectious Diseases, and Hospital Epidemiology Symposium, Boston, October 22-24, 1987.

12. Self-reported changes in sexual behaviors among homosexual and bisexual men from the San Francisco City Clinic cohort. MMWR $1987 ; 36: 187-189$

13. New Jersey State Department of Health, CN360. NJ State Bull Trenton, NJ, December 1, 1987.

14. New Jersey State Department of Health, CN 360 . NJ State Bull Trenton, NJ, March 1, 1987.

15. Antibody to human immunodeficiency virus in female prostitutes. MMWR 1987;36:157-161.

16. Barnish M, Conduluci DV. AIDS in New Jersey. $J$ NJ Osteopath Physicians Surgeons 1987;86:8-10.

From the Department of Medicine, Division of Infectious Diseases, University of Medicine and Dentistry of New JerseySchool of Osteopathic Medicine, Stratford, NJ.

Reprint requests to Dr Condoluci, Division of Infectious Diseases, Kennedy Professional Center, Suite 108, 40 E Laurel Rd, Stratford, NJ 08034 